\title{
Role of a Compatibilizer in the Structure and Micromechanical Properties of Recycled Poly(ethylene terephthalate)/Polyolefin Blends with Clay
}

\author{
A. Hellati, ${ }^{1}$ D. Benachour, ${ }^{1}$ M. E. Cagiao, ${ }^{2}$ S. Boufassa, ${ }^{3}$ F. J. Baltá Calleja ${ }^{2}$ \\ ${ }^{1}$ Laboratoire des Matériaux Polymériques Multiphasiques, Department of Process Engineering, \\ Faculty of Engineering, Ferhat Abbas University, Sétif 19000, Algeria \\ ${ }^{2}$ Instituto de Estructura de la Materia, Consejo Superior de Investigaciones Científicas, Serrano 119, \\ Madrid 28006, Spain \\ ${ }^{3}$ Department of Process Engineering, Faculty of Engineering, Ferhat Abbas University, Sétif 19000, Algeria
}

Received 20 November 2009; accepted 13 January 2010

DOI 10.1002/app.32090

Published online 3 June 2010 in Wiley InterScience (www.interscience.wiley.com).

\begin{abstract}
The comparison of the degree of crystallinity and the micromechanical properties in the blends of recycled amorphous poly(ethylene terephthalate) (PET) with isotactic polypropylene (iPP) and high-density polyethylene (HDPE) with a compatibilizer in different proportions is reported. The physical study of the composites of the compatibilized blends and clay is also discussed. The analysis, performed by means of wide-angle X-ray scattering and differential scanning calorimetry techniques, permits us to describe, at microscale level, the role of the compatibilizer on the structure and microhardness of the polymer blends that we studied. The results reveal that PET was incompatible with both iPP and HDPE. However, the presence of the compatibilizer, a styrene-ethylene/
\end{abstract}

butylene-styrene block copolymer grafted with maleic anhydride, allowed the compatibilization of these polymers. In the PET/iPP blends, the clay seemed to have a nucleating effect on the iPP and also induced a hardness increase in the compatibilized blends. On the other hand, in case of PET/ HDPE, the crystallinity of these samples (pure blends, blends with compatibilizer, and blends with compatibilizer plus clay) only depended on their composition. Similarly to the PET/iPP blends, the addition of clay induced an increase in the hardness of the compatibilized blends. (C) 2010 Wiley Periodicals, Inc. J Appl Polym Sci 118: 1278-1287, 2010

Key words: blends; compatibilization; differential scanning calorimetry (DSC); hardness; WAXS

\section{INTRODUCTION}

During recent decades, interest in the recycling of polymeric materials has experienced a notable increase for both economical and environmental reasons. ${ }^{1,2}$ However, recycled polymers are subjected to thermal and mechanical processes that give rise to structural and morphological changes, which, consequently, affect the properties of the materials. A way of improving the properties of recycled polymers is to blend them with unmodified polymers. In fact, the preparation of polymer blends is a convenient way to obtain materials with new combinations of defined properties. ${ }^{3-5}$ These properties are closely related to the microstructure of the polymeric blend. We have

Correspondence to: F. J. Baltá Calleja (embalta@iem.cfmac. sic.es).

Contract grant sponsor: Spanish Ministry of Science and Innovation; contract grant number: FIS2007-60534.

Contract grant sponsor: Centre Universitaire Bordj Bou Arreridj (to A.H. to cover his expenses during his stay in Madrid).

Journal of Applied Polymer Science, Vol. 118, 1278-1287 (2010)

(C) 2010 Wiley Periodicals, Inc. focused our attention on blends of recycled amorphous poly(ethylene terephthalate) (PET) with isotactic polypropylene (iPP) or high-density polyethylene (HDPE). However, as with most thermoplastics, these polymers are immiscible and need to be made compatible. ${ }^{6}$ In this study, we used as a compatibilizer a styrene-ethylene/butylene-styrene block copolymer grafted with maleic anhydride (SEBSMAH). In addition, we compared PET/iPP/ SEBS-MAH blends and PET/HDPE/SEBS-MAH blends with their corresponding composites containing 3 or $5 \mathrm{wt} \%$ clay. As it is known, the addition of small amounts of layered silicates, that is, clay, to the polymers greatly improved some of their properties, that is, their strength, heat resistance, impact resistance, and so on. ${ }^{7}$ However, the preparation of a homogeneous dispersion of clay particles (hydrophilic) in a nonpolar polymer matrix is a difficult process. The clay particles tend to agglomerate, and the physical properties of the resulting material tend to be very poor. To solve this problem, as a first step, the surfaces of the clay have to be previously modified with some organophilic agent, that is, quaternary ammonium salts ${ }^{8}$ or long-chain primary amines, that is, octadecylamine. ${ }^{9}$ The resulting material is called 
organophilic clay or organoclay. This process lowers the surface energy of the silicate surface and improves the wetting with the polymer matrix. ${ }^{10}$ Thus, organosilicates are more compatible with most engineering plastics than is unmodified material. The second step is the preparation of the polymer-organoclay composites. This can be achieved by the mixing of the organoclay with the molten polymers (melt-mixing method, see the detailed procedure given later), among other methods.

Much work has been done in the study of the mechanical properties of multicomponent systems in relation to their composition and phase. ${ }^{11}$ One of the simplest ways to measure the micromechanical properties of a material is by the use of the indentation test. ${ }^{12}$ This technique is very sensitive to the changes that take place in the morphology and microstructure of polymers and has been successfully applied to many different systems. Thus, in preceding investigations, the study of the microindentation hardness $(H)$ of blends of semicrystalline polymers, ${ }^{13,14}$ amorphous systems, ${ }^{15}$ block copolymers, ${ }^{16,17}$ and natural rubber blends ${ }^{18,19}$ has been reported. In addition, the influence of a compatibilizer on the interphase boundary and the micromechanical behavior of polymer blends of polystyrene and natural rubber ${ }^{20}$ have been examined. Also, the influence of the presence of a compatibilizer on the microhardness has been discussed. ${ }^{21}$ Finally, the correlation between the morphology and micromechanical properties of ethylene/1-octene copolymers and their blends with HDPE has also been reported..$^{22}$ Recent investigations have been concerned with the structure and properties of new, reversibly crosslinked iPP/LDPE blends. ${ }^{23}$

The aim of this study was to examine the influence of a compatibilizer on the structure and micromechanical properties of PET/iPP and PET/HDPE blends with clay. As discussed later, the clay appeared to have a nucleation effect on iPP, inducing a clear hardness increase in the compatibilized blends.

\section{EXPERIMENTAL}

\section{Materials}

The following materials were used in this investigation: recycled material from PET bottles (melting range of $242-250^{\circ} \mathrm{C}$ ); Bangkok Polyester Public Co., Bangkok (Thailand); commercial grade iPP EMB 13014C, Montell, Milan (Italy); HDPE 5502 BK0904, Polymed, Skikda (Algeria), and SEBS-MAH compatibilizer KRATON FG-1901X, Shell, The Hague (Netherlands). The organophilic clay has been prepared in our laboratory by using bentonite (a montmorillonite-type silicate) which was supplied by Bental, Algiers (Algeria); the preparation method is described next.

\section{Organophilic clay preparation}

The raw bentonite was first crushed and then filtered to eliminate impurities. Then, $30 \mathrm{~g}$ was dispersed in $1 \mathrm{~L}$ of a sodium chloride $(\mathrm{NaCl})$ solution $(1 N)$, and the mixture was stirred for $24 \mathrm{~h}$; this operation was repeated four times. The suspension obtained was washed with distilled water several times until chloride ions completely disappeared, and then, the suspension was left for $48 \mathrm{~h}$ to be decanted. After sedimentation, the suspension was centrifuged, dried, and finally crushed. The obtained powder $(5 \mathrm{~g})$ was spread in a hot solution $\left(80^{\circ} \mathrm{C}\right)$ containing $2.3 \mathrm{~g}$ of octadecylamine $\left(\mathrm{C}_{18} \mathrm{H}_{39} \mathrm{~N}\right)$, and the mixture was stirred for $3 \mathrm{~h}$. To eliminate the organic cations, the suspension obtained was washed several times with a water/ethanol $50 / 50$ mixture at $60^{\circ} \mathrm{C}$. The organophilic montmorillonite thus obtained was dried for $36 \mathrm{~h}$ before it was crushed and stored.

\section{Blend preparation}

Before blending, the PET pellets were dried in vacuo at $105^{\circ} \mathrm{C}$ for $24 \mathrm{~h}$. The dried PET pellets were dry-mixed with iPP or HDPE pellets in the following weight ratios: $20 / 80,40 / 60,50 / 50,60 / 40$, and 80/20. The blends were prepared in a Brabender Haake Rheocord (Cergy-Pontoise, France), at $270^{\circ} \mathrm{C}$ and $32 \mathrm{rpm}$ in two steps; first, the PET was fed into the chamber, and once the PET melted, the IPP (or the HDPE), the compatibilizer, and the organoclay were added.

From the preceding blends, films were prepared by compression molding in a Zwick machine (Ulm, Germany), model 7102, working at a pressure of $150 \mathrm{~kg} /$ $\mathrm{cm}^{2}$ ). The compression was performed at $275^{\circ}$ during 6 $\min$ (4 min for preheating and $2 \mathrm{~min}$ for compression).

Two series of blends were examined in this study:

1. Blends of amorphous PET with iPP without and with the SEBS-MAH compatibilizer. These included the following samples:

a. PET/iPP blends without compatibilizer.

b. PET/iPP blends with 7,10 , and $15 \%$ compatibilizer.

c. PET/iPP blends with $15 \%$ compatibilizer and $5 \%$ clay.

2. Blends of amorphous PET with HDPE without and with SEBS-MAH compatibilizer. These included the following samples:

a. PET/HDPE blends without compatibilizer.

b. PET/HDPE blends with $15 \%$ compatibilizer.

c. PET/HDPE blends with 7,10 , and $15 \%$ compatibilizer plus 3 or $5 \%$ clay.

\section{Techniques}

The wide-angle X-ray scattering (WAXS) study was carried out with a Seifert (Ahrensburg, Germany) 
diffractometer working in the reflection mode. The experimental conditions were the following: Ni-filtered $\mathrm{Cu} \mathrm{K} \alpha$ radiation with a wavelength of 0.15418 $\mathrm{nm}, 40 \mathrm{kV}$ and $35 \mathrm{~mA}$, angular range $(2 \theta)=5-35^{\circ}$, and scan rate $=0.02^{\circ} / \mathrm{s}$. The WAXS-determined crystallinity $\left(\alpha_{\text {WAXS }}\right)$ of every sample was calculated as the ratio of the area corresponding to the crystalline peaks to the total area of the diffractogram.

The thermal study was performed with help of a Perkin Elmer (Norwalk, Connecticut, USA) DSC-7 differential scanning calorimetry (DSC) instrument in an inert $\mathrm{N}_{2}$ atmosphere. Sample weights were 5$10 \mathrm{mg}$. The temperature range studied was 50$300^{\circ} \mathrm{C}$. The heating rate was $10^{\circ} \mathrm{C} / \mathrm{min}$. The crystallinity measured by DSC ( $\left.\alpha_{\mathrm{DSC}}\right)$ was derived from the melting enthalpy obtained by DSC with the following expression:

$$
\alpha_{\mathrm{DSC}}=\Delta H_{m} / \Delta H_{m}^{\infty}
$$

where $\Delta H_{m}$ and $\Delta H_{m}^{\infty}$ are the experimental melting enthalpy and the melting enthalpy for an infinitely thick crystal, respectively.

$H$ was determined at room temperature with a Leitz (Wetzlar, Germany) microindentation tester with a square-based diamond indenter. The $H$ value was derived from the residual projected area of indentation according to the following expression: ${ }^{12}$

$$
H=k P / d^{2}
$$

where $d$ is the length of the impression diagonal $(\mathrm{m}), P$ is the contact load applied $(\mathrm{N})$, and $k$ is a geometrical factor equal to 1.854. Loads of 0.5 and $1 \mathrm{~N}$ were applied. The loading cycle was $0.1 \mathrm{~min}$. Eight to10 indentations were performed on the surface of each sample, and the results were averaged.

\section{RESULTS AND DISCUSSION}

\section{PET/iPP blends}

\section{Blends without clay}

The majority of the WAXS diagrams obtained for the different blends showed broad halos and narrow peaks corresponding to the iPP $\alpha$ form [see Fig. 1(a,b)]. The diffractogram of the PET/iPP $80 / 20$ blend without compatibilizer only exhibited the main crystalline reflection of iPP at about $14.2^{\circ}(2 \theta)$, superposed to a broad halo from PET [see Fig. 1(a)], whereas the diffractograms of the blends with the same composition plus 7 or $10 \%$ compatibilizer (not shown here) showed totally amorphous halos. In addition, only some compatibilized blends with a 50/50 composition (not presented here) exhibited, together with those of iPP, other peaks that were attributed to a certain content of crystallized PET.
For most compositions, together with the iPP melting peak, both the crystallization and melting peaks of the PET component appeared in the thermograms [see Fig. $2(a, b)$ ]. For the $\alpha_{D S C}$ calculation, we took the following values: $\Delta H_{m}^{\infty}=140.1 \mathrm{~J} / \mathrm{g}^{24}$ for PET and $\Delta H_{m}^{\infty}=207.33 \mathrm{~J} / \mathrm{g}^{24}$ for iPP.

As indicated previously, in most of the WAXS diagrams of the blends, only the crystalline reflections of the iPP component appeared (see Fig. 1). Nevertheless, in the corresponding thermograms, the enthalpic balance for the PET component, that is, the
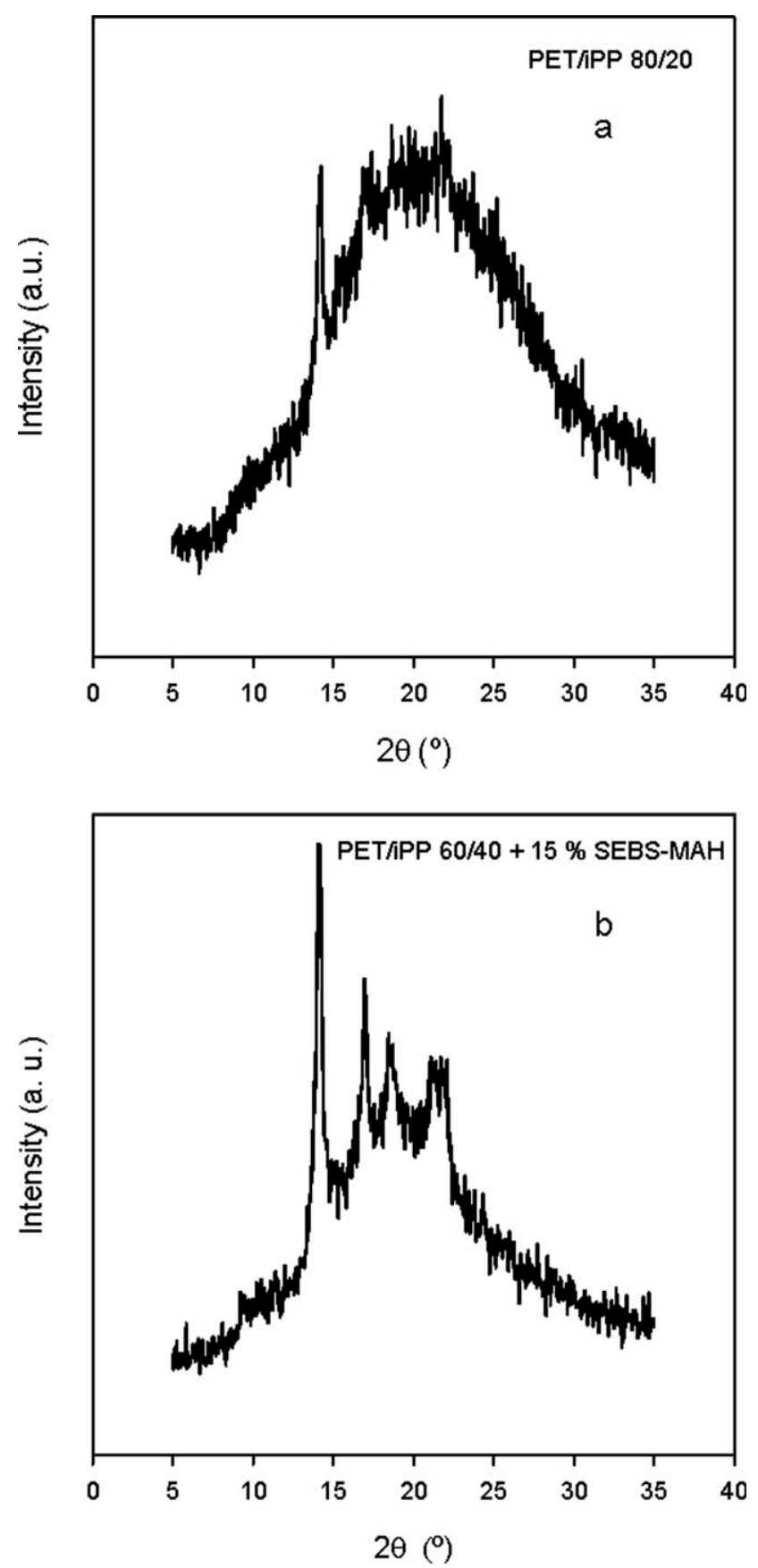

Figure 1 X-ray diffractograms of the blends: (a) $80 / 20$ PET/iPP and (b) 60/40 PET/iPP with 15\% compatibilizer. 

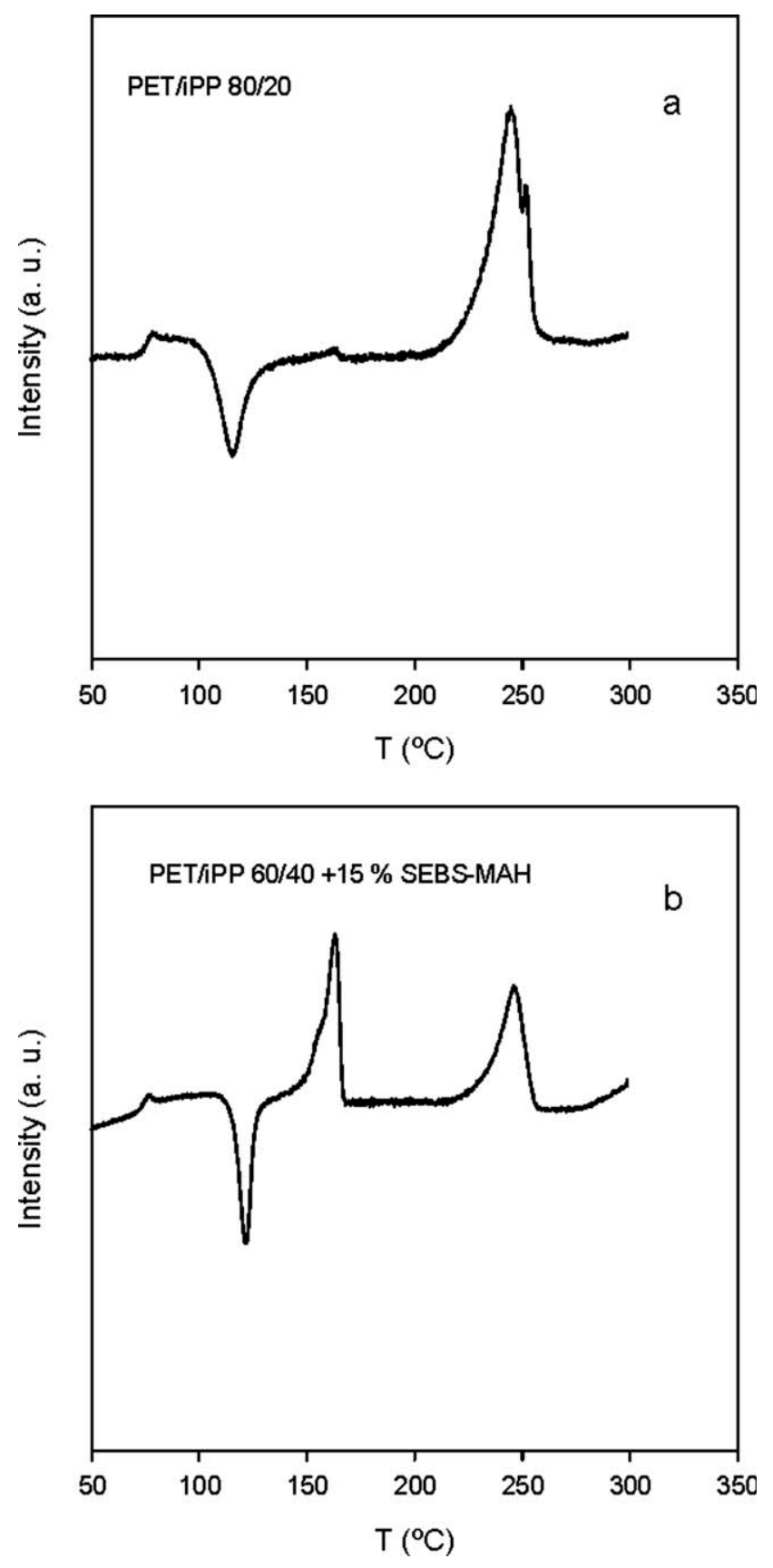

Figure 2 DSC thermograms of the blends in Figure 1 ( $T=$ temperature).

difference between the melting enthalpy and the crystallization enthalpy was always positive. Thus, it seemed that the blending process gave rise to the crystallization of a certain amount of the initially amorphous PET component, even when the crystalline PET peaks were not detected in the diffractograms. For this reason, the total crystallinity (calculated for both iPP and PET components, results not shown here) derived from the thermograms was slightly higher than that calculated for the iPP alone. The DSC analysis also indicated that the melting temperatures $\left(T_{m}{ }^{\prime} \mathrm{s}\right)$ of iPP and PET in the uncompa- tibilized and compatibilized blends were almost the same as those of the pure components, that is, $T_{m}=$ $163-164^{\circ} \mathrm{C}$ for iPP and $T_{m}=246-247^{\circ} \mathrm{C}$ for PET. Hence, the crystal thickness $\left(l_{c}\right)$ of the components, derived from the Thomson-Gibbs equation [eq. (2)], was not affected by the blending process:

$$
T_{m}=T_{m}^{0}\left[1-\left(2 \sigma_{e} / \Delta H_{m}^{\infty} l_{c}\right)\right]
$$

where $\sigma_{e}$ is the surface free energy and $T_{m}^{0}$ is the equilibrium melting point of each component. For $\mathrm{iPP}$, we took $T_{m}^{0}=460.7^{\circ} \mathrm{K}^{24}$ and $\sigma_{e}=100 \mathrm{erg} /$ $\mathrm{cm}^{2,25}$ for the PET component, we used $T_{m}^{0}=553^{\circ}$ $\mathrm{K}^{24}$ and $\sigma_{e}=151-161 \mathrm{erg} / \mathrm{cm}^{2}{ }^{26}$ The $l_{c}$ values obtained from eq. (2) for both components were 26 $\mathrm{nm}$ for PET and $19 \mathrm{~nm}$ for iPP. On the other hand, the crystallization temperatures measured for the PET component shifted to lower values (minimum of $115^{\circ} \mathrm{C}$ ) compared to the neat PET, that is, $125^{\circ} \mathrm{C}$.

As shown in Table I and Figure 3(a), the presence of the amorphous PET induced a decrease in the crystallinity of the pure iPP/PET blends, from $50 \%$

TABLE I

Pure PET/PP Blends and Blends with SEBS-MAH as a Compatibilizer

\begin{tabular}{lll}
\hline \multicolumn{1}{c}{ Composition } & $\begin{array}{c}\text { Total } \\
\text { crystallinity } \\
\text { (WAXS) }\end{array}$ & $\begin{array}{c}\text { iPP } \\
\text { crystallinity } \\
\text { (DSC) }\end{array}$ \\
\hline 100/0 PET/PP & 0.00 & 0.00 \\
80/20 PET/PP & 0.04 & 0.003 \\
50/50 PET/PP & 0.12 & 0.04 \\
20/80 PET/PP & 0.09 & 0.07 \\
0/100 PET/PP & 0.50 & 0.40 \\
100/0 PET/PP + 7\% compatibilizer & 0.00 & 0.00 \\
80/20 PET/PP + 7\% compatibilizer & 0.00 & $0.00^{\mathrm{a}}$ \\
60/40 PET/PP + 7\% compatibilizer & 0.04 & 0.07 \\
50/50 PET/PP + 7\% compatibilizer & 0.19 & 0.15 \\
40/60 PET/PP + 7\% compatibilizer & 0.18 & 0.19 \\
20/80 PET/PP + 7\% compatibilizer & 0.41 & $0.31^{\mathrm{b}}$ \\
0/100 PET/PP + 7\% compatibilizer & 0.51 & 0.40 \\
100/0 PET/PP + 10\% compatibilizer & 0.00 & 0.00 \\
80/20 PET/PP + 10\% compatibilizer & 0.00 & 0.04 \\
50/50 PET/PP + 10\% compatibilizer & $0.40^{\mathrm{c}}$ & $0.17^{\mathrm{a}}$ \\
40/60 PET/PP + 10\% compatibilizer & 0.15 & 0.25 \\
20/80 PET/PP + 10\% compatibilizer & 0.46 & $0.25^{\mathrm{d}}$ \\
100/0 PET/PP + 15\% compatibilizer & 0.00 & 0.00 \\
80/20 PET/PP + 15\% compatibilizer & 0.08 & 0.05 \\
60/40 PET/PP + 15\% compatibilizer & 0.18 & 0.15 \\
50/50 PET/PP + 15\% compatibilizer & 0.22 & $0.19^{\mathrm{d}}$ \\
40/60 PET/PP + 15\% compatibilizer & 0.21 & 0.17 \\
20/80 PET/PP + 15\% compatibilizer & 0.41 & $0.28^{\mathrm{d}}$ \\
0/100 PET/PP + 15\% compatibilizer & 0.43 & 0.32 \\
\hline
\end{tabular}

$\mathrm{PP}=$ polypropylene.

a Only the crystallization and melting peaks of PET appear.

${ }^{\mathrm{D}}$ Only the melting peak of PP appears.

c Appearance of additional peaks in the WAXS diagram.

$\mathrm{d}$ Appearance of the PP and PET melting peaks but not of the PET crystallization peak. 

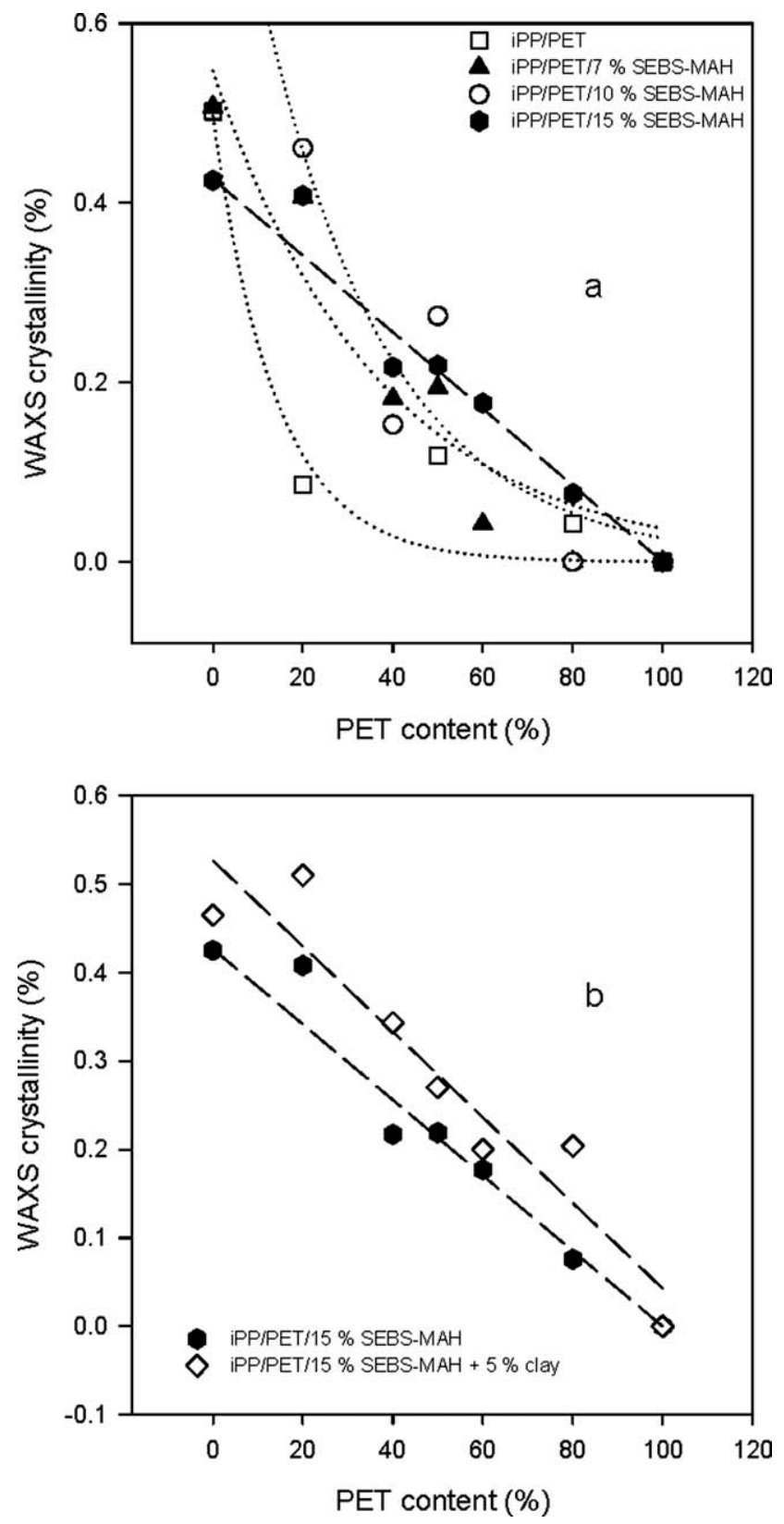

Figure 3 Plot of $\alpha_{\text {WAXS }}$ as a function of the PET content: (a) PET/iPP blends (pure and with different amounts of the compatibilizer) and (b) PET/iPP blends with 15\% compatibilizer (pure and with $5 \%$ clay).

for pure iPP down to less than $5 \%$ for the $20 / 80$ composition $\left(\alpha_{\text {WAXS }}\right)$ or from $40 \%$ down to less than $1 \%\left(\alpha_{\mathrm{DSC}}\right.$, data not shown here). In all cases, the $\alpha_{\text {DSC }}$ values included in Tables I and II were calculated only for the iPP component. The $\alpha_{\text {WAXs }}$ values were slightly higher than those obtained by DSC (see Table I for comparison). When the SEBS-MAH compatibilizer was added, the crystallinity level of the blends increased again. In fact, the $\alpha_{\mathrm{WAXS}}$ values obtained for blends with $15 \%$ compatibilizer practically followed the additivity law [dashed line in Fig. 3(a)] as a function of composition. Blends with 7 and
$10 \%$ SEBS-MAH, however, showed $\alpha_{\text {WAXS }}$ values that were smaller than that predicted by this law [see Fig. 3(a) and Table I]. $H$ of the blends without compatibilizer showed a linear behavior. $H$ rose with increasing PET content [see Fig. 4(a)] according to the additivity law of a binary blend as a function of composition:

$$
H=H_{1} \Phi_{1}+H_{2}\left(1-\Phi_{1}\right)
$$

where $H_{1}, H_{2}, \Phi_{1}$, and $1-\Phi_{1}$ are the hardness values of the blend components and their molar fractions, respectively. However, the results obtained for the blends with compatibilizer showed a decrease in hardness with increasing PET content up to the equivolumic composition (50/50), and for larger PET content values, $H$ increased again. Also, the hardness of the blends decreased with increasing amounts of compatibilizer.

On the other hand, according to the two-phase model, $H$ of a semicrystalline polymer can be described by the following expression: ${ }^{27}$

$$
H=H_{c} \alpha+H_{a}(1-\alpha)
$$

where $H_{c}$ and $H_{a}$ are the intrinsic hardness values of the crystalline and amorphous phases, respectively, and $\alpha$ is the volume fraction of the crystalline material.

By combining eqs. (3) and (4), we obtain the following: ${ }^{27}$

$$
H=H^{\mathrm{PET}} \Phi_{1}+\left[H_{c}^{\mathrm{iPP}} \alpha^{\mathrm{iPP}}+H_{a}^{\mathrm{iPP}}(1-\alpha)\right]\left(1-\Phi_{1}\right)
$$

$\alpha^{\mathrm{iPP}}$ is the degree of crystallinity of iPP; $H_{c}^{\mathrm{iPP}}$ and $H_{a}^{\mathrm{iPP}}$ are the intrinsic hardness values of the crystalline and amorphous phases of iPP, respectively; and $H^{\text {PET }}$ is the microindentation hardness of PET. This expression takes into account $H_{c}$ and $H_{a}$ of every component, their $\alpha$ values, and the compositions of the blends. Here, again, the blends with compatibilizer showed $H$ values that were notably lower than the ones derived from the additivity law according to eq. (5).

From the foregoing, it is clear that the two main effects to be considered when the compatibilizer was added to these blends were the increase in the crystallinity and the simultaneous decrease in their hardness. Both effects could be associated with the presence of the SEBS-MAH compatibilizer. On one hand, one may think that the compatibilizer contributed to an increase of the iPP chain flexibility so that they could crystallize more easily. On the other hand, the hardness diminution in the compatibilized samples could have been explained by the decrease in $H_{c}^{\mathrm{iPP}}$. The relationship between $H_{c}$ and $l_{c}$ is ${ }^{27}$ 
TABLE II

PET/PP/SEBS-MAH Blends with 5\% Clay

\begin{tabular}{lcc}
\hline \multicolumn{1}{c}{ Composition } & $\begin{array}{c}\text { Total crystallinity } \\
\text { (WAXS) }\end{array}$ & $\begin{array}{c}\text { iPP crystallinity } \\
\text { (DSC) }\end{array}$ \\
\hline 100/0 PET/PP + 15\% compatibilizer + clay & 0.00 & 0.00 \\
80/20 PET/PP + 15\% compatibilizer + clay & 0.20 & 0.07 \\
60/40 PET/PP + 15\% compatibilizer + clay & 0.20 & 0.11 \\
50/50 PET/PP + 15\% compatibilizer + clay & 0.27 & 0.11 \\
40/60 PET/PP + 15\% compatibilizer + clay & 0.34 & 0.17 \\
20/80 PET/PP + 15\% compatibilizer + clay & 0.51 & 0.20 \\
0/100 PET/PP + 15\% compatibilizer + clay & 0.47 & 0.40 \\
$50 / 50$ PET/PP + 7\% compatibilizer + clay & $0.45^{\mathrm{a}}$ & 0.18 \\
$50 / 50$ PET/PP + 10\% compatibilizer + clay & $0.41^{\mathrm{a}}$ & 0.12 \\
\hline
\end{tabular}

$\mathrm{PP}=$ polypropylene.

a Appearance of additional peaks in the WAXS diagram.

$$
H_{c}=H_{c}^{\infty} /\left(1+b / l_{c}\right)
$$

where $H_{c}^{\infty}$ is the hardness for an infinitely thick crystal and parameter $b$ is defined as $b=2 \sigma_{e} / \Delta h$. In this expression, $\Delta h$ is the energy required to plastically deform the crystalline lamellar stacks.

As $l_{c}$ for both components remained practically constant in all compositions, the diminution in the $H_{c}$ value for the iPP component could be explained by an increase in parameter $b$ [eq. (6)] through $\sigma_{e}$, which is known to be related with the degree of order at the crystal surface. ${ }^{27}$ Thus, the $b$ increase might have originated from the blending process of the samples; by the disorder created in the crystals surface due to the presence of amorphous chains of elastomeric character, originating from the compatibilizer, ${ }^{14}$ or by a combination of both effects.

\section{Blends with 5\% clay}

From the results shown in Figure 3(b) and Table II, we deduced that the presence of $5 \mathrm{wt} \%$ clay in the blends with $15 \%$ compatibilizer increased $\alpha_{\text {WAXS }}$ by, approximately, 5-10\% (see Tables I and II). As happened in their counterparts without clay, the $\alpha_{\text {WAXS }}$ values obtained for these blends obeyed the additivity law as a function of composition [see Fig. 3(b)]. Thus, it is feasible that the presence of the clay had a nucleating effect over the crystallizability of the iPP component. On the other hand, as it happened in the blends of the $a$ and $b$ series, the enthalpic balance for the PET component was positive for all of the compositions. The $H$ values of the blends containing clay were higher than their counterparts without clay. However, the hardness dependence with the PET content was similar in both sets of blends [see Fig. 4(b)]. In the blends of the c series, the theoretical hardness values calculated by eq. (5) were not very far from the experimental ones (for compositions up to $50 / 50$ ).
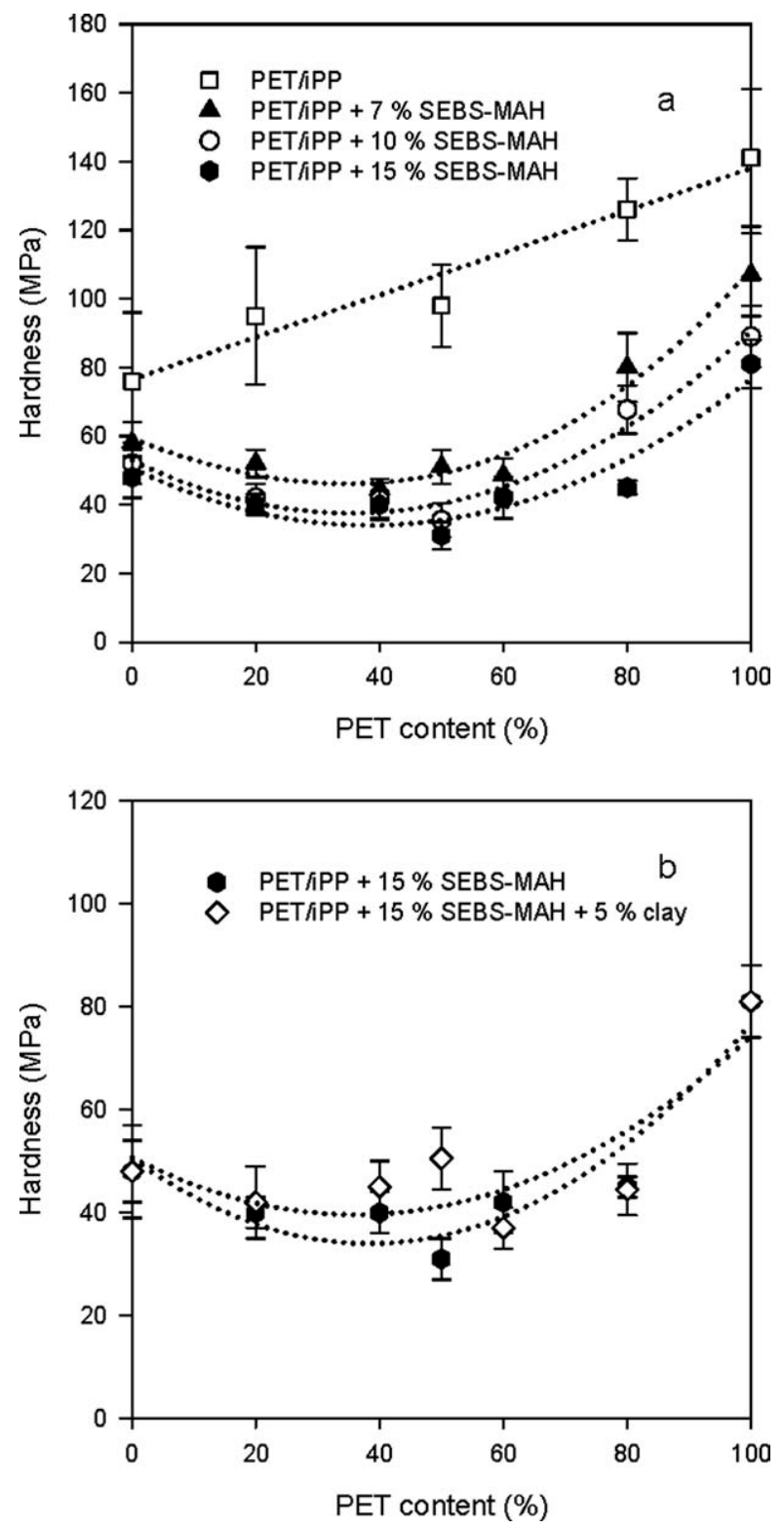

Figure 4 Dependence of the hardness on the PET content: (a) PET/iPP blends (pure and with different amounts of the compatibilizer) and (b) PET/iPP blends with $15 \%$ compatibilizer (pure and with 5\% clay). 

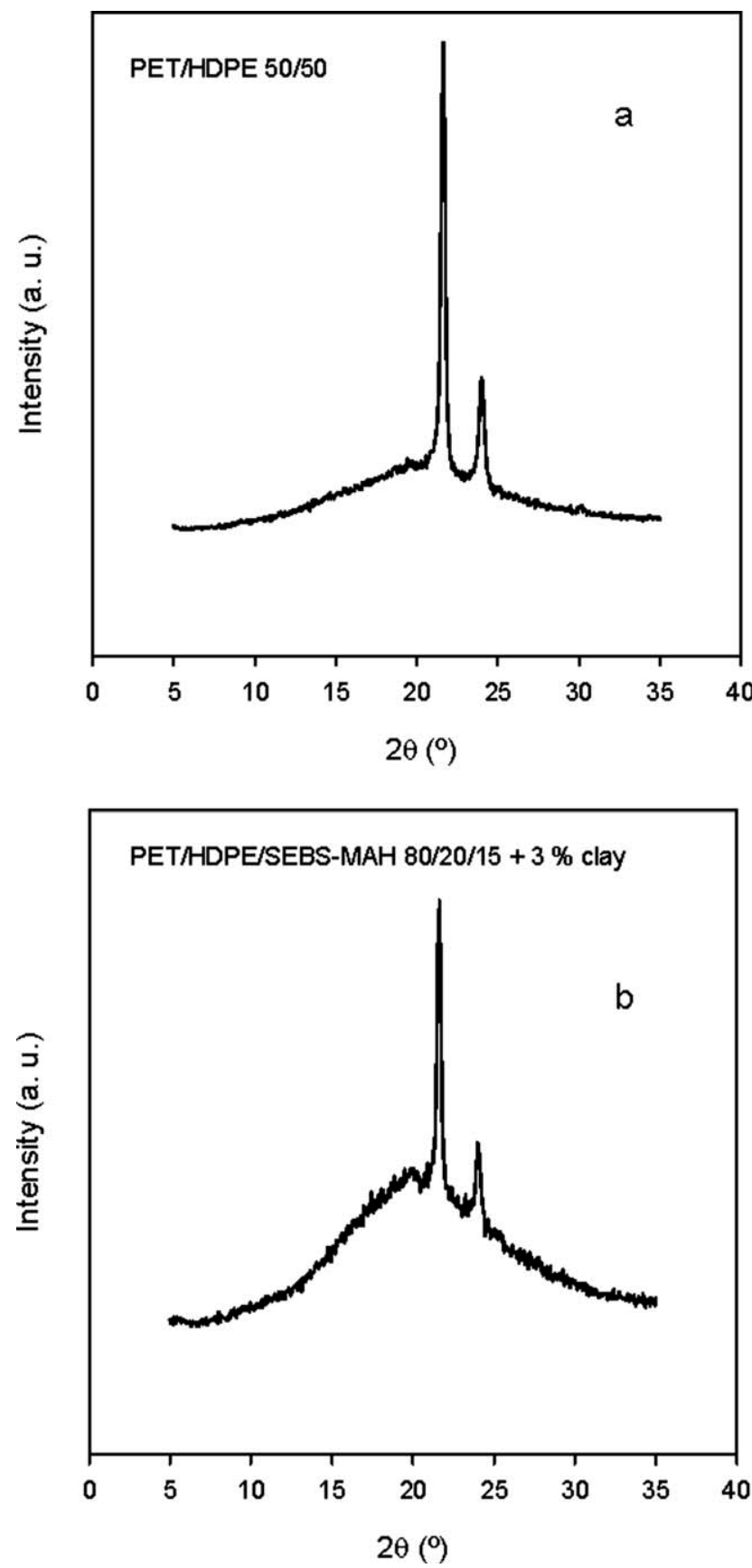

Figure 5 WAXS diffractograms of the following blends: (a) 50/50 PET/HDPE and (b) 80/20 PET/HDPE with 15\% compatibilizer and $3 \%$ clay.

The same as in the a and b series, in the c series, the $T_{m}$ values of both components remained constant for all compositions and were practically equal to the values found for the pure components (see previous discussion). This means that the $l_{c}$ values also remained constant and equal to 26 and $19 \mathrm{~nm}$ for the PET and IPP, respectively. Therefore, the decrease in the measured $H$ in the blends with compatibilizer plus clay could be explained again as due to the decrease in $H_{c}$ of the iPP component. As happened in the $a$ and $b$ series, this probably originated by the increase in the $b$ parameter [eq. (6)] through $\sigma_{e}$ in the iPP crystals, which finally was related to the blending process of the samples and to the presence of an amorphous compatibilizer. ${ }^{14}$ However, this effect was smaller in the blends with clay [see Fig. 4(b)].

\section{PET/HDPE blends}

The WAXS diagrams for all compositions only showed the HDPE crystalline reflections [see Fig. $5(a, b)]$. However, in most of the thermograms, we
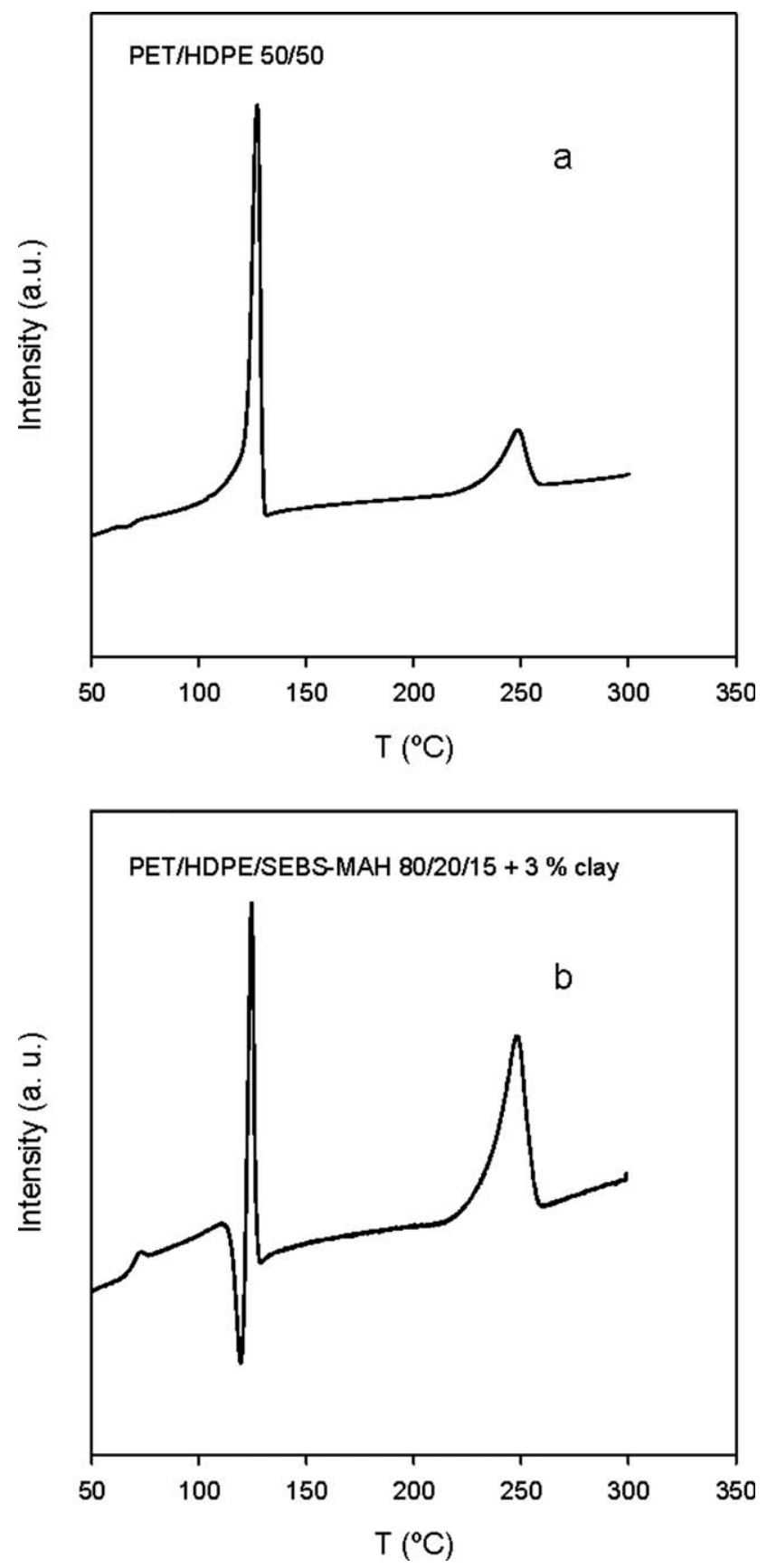

Figure 6 Thermograms of the blends in Figure $5(T=$ temperature). 

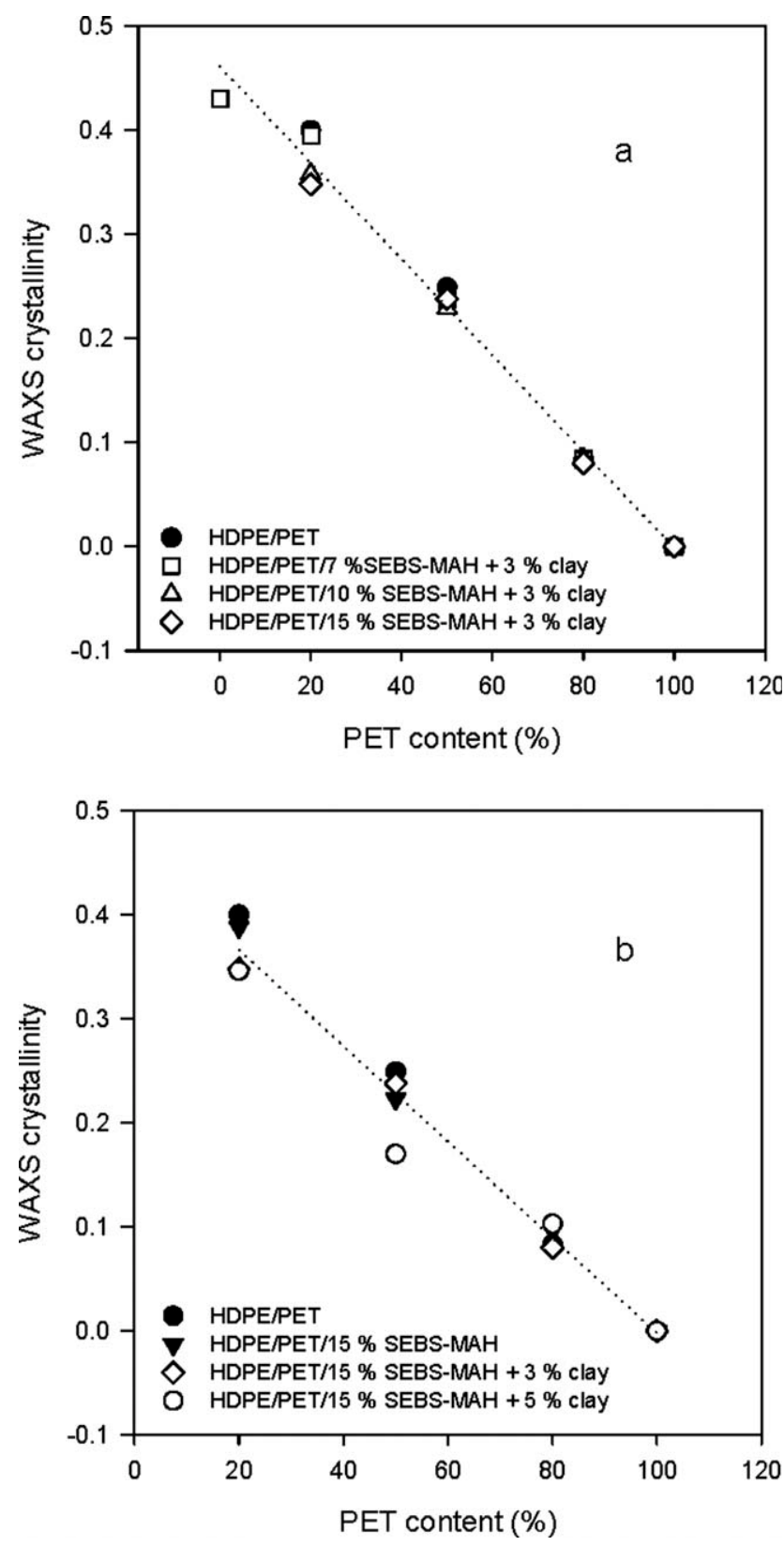

Figure 7 Dependence of $\alpha_{\text {WAXS }}$ on the PET content: (a) PET/HDPE blends (pure and with different proportions of the compatibilizer plus $3 \%$ clay) and (b) PET/HDPE blends (pure, with 15\% compatibilizer, and with 15\% compatibilizer and 3 or $5 \%$ clay).

could distinguish, together with the melting peak of HDPE, the crystallization and/or melting peaks of the PET component [see Fig. 6(a,b)]. As happened in the case of the PET/iPP blends, the enthalpic balance for the PET component was always positive. Thus, the total crystallinity derived from the thermograms for both components, HDPE and PET (results not shown here), was higher than the one derived for the HDPE alone. According to the thermograms, the $T_{m}$ values of both components remained practically constant for all of the compositions and were identical to those of the pure polymers. Thus, for HDPE, $T_{m}=127-128^{\circ} \mathrm{C}$ in the blends without clay, and $T_{m}=124-125^{\circ} \mathrm{C}$ in the blends containing clay. In addition, $T_{m}$ for the PET was equal to $247-248^{\circ} \mathrm{C}$. Therefore, $l_{c}$ of the components was practically not affected by the blending process. For the calculation of the $l_{c}$ value of every component, we again used the Thomson-Gibbs equation [eq. (2)], taking for the HDPE $T_{m}^{0}=414.6^{\circ} \mathrm{K}^{24}$ and $\sigma_{e}=79 \mathrm{erg} / \mathrm{cm}^{2} .{ }^{28}$ Thus, the $l_{c}$ value derived for PET was $26 \mathrm{~nm}$, as in the PET/iPP blends, and for the HDPE, was $15.2 \mathrm{~nm}$. The crystallization temperatures obtained for the PET component shifted slightly to lower values $\left(119^{\circ} \mathrm{C}\right)$ compared to the neat PET $\left(125^{\circ} \mathrm{C}\right)$.

For all the compositions (pure blends, blends with compatibilizer, and blends with compatibilizer plus clay), $\alpha_{\text {WAXs }}$ decreased as the PET content increased [see Figs. $7(a, b)$ and Tables III and IV]. The presence of the compatibilizer (or the compatibilizer plus clay) did not seem to affect $\alpha_{\text {WAXS }}$ of the samples [see Figs. $7(a, b)] . \alpha_{\mathrm{HDPE}}$, derived from the DSC study and calculated with $\Delta H_{m}^{\infty}=293.86 \mathrm{~J} / \mathrm{g}^{24}$ for HDPE, also decreased linearly when the PET content increased (see Tables III and IV).

$H$ of the blends increased and deviated from linearity with increasing amounts of PET. The presence of SEBS-MAH gave rise to a hardness diminution, more notable when the content of the compatibilizer increased [see Fig. 8(a)]. The addition of clay to the blends with compatibilizer seemed to have the contrary effect [see Fig. 8(b)]. There were no large differences in the hardness of blends with 3 or $5 \%$ clay. The $H$ values for the pure blends were lower than the derived by the application of the additivity law; we took into account the crystalline and amorphous hardness, the crystallinity of every component, and the blend composition [eq. (5)]. The blends with 15\%

TABLE III

Pure PET/HDPE Blends and Blends with SEBS-MAH as a Compatibilizer

\begin{tabular}{lcc}
\hline \multicolumn{1}{c}{ Composition } & $\begin{array}{c}\text { Total } \\
\text { crystallinity } \\
\text { (WAXS) }\end{array}$ & $\begin{array}{c}\text { HDPE } \\
\text { crystallinity } \\
\text { (DSC) }\end{array}$ \\
\hline 100/0 PET/HDPE & 0.00 & 0.00 \\
80/20 PET/HDPE & 0.08 & 0.04 \\
50/50 PET/HDPE & 0.25 & $0.27^{\mathrm{a}}$ \\
20/80 PET/HDPE & 0.40 & $0.49^{\mathrm{a}}$ \\
100/0 PET/HDPE $+15 \%$ & 0.00 & 0.00 \\
$\quad$ compatibilizer & & \\
80/20 PET/HDPE $+15 \%$ & 0.10 & 0.07 \\
$\quad$ compatibilizer & 0.22 & $0.21^{\mathrm{a}}$ \\
50/50 PET/HDPE $+15 \%$ & & $0.43^{\mathrm{a}}$ \\
$\quad$ compatibilizer & 0.39 & \\
20/80 PET/HDPE $+15 \%$ & & \\
compatibilizer & &
\end{tabular}

a Appearance of the polyethylene and PET melting peaks but not of the PET crystallization peak. 
TABLE IV

PET/HDPE/SEBS-MAH Blends with 3 or $5 \%$ Clay

\begin{tabular}{lcc}
\hline \multicolumn{1}{c}{ Composition: } & $\begin{array}{c}\text { Total } \\
\text { crystallinity } \\
\text { PET } / \text { HDPS }\end{array}$ & $\begin{array}{c}\text { HDPE } \\
\text { crystallinity } \\
\text { (DSC) }\end{array}$ \\
\hline 100/0/7 + 3\% clay & 0.00 & 0.00 \\
$80 / 20 / 7+3 \%$ clay & 0.08 & 0.03 \\
$50 / 50 / 7+3 \%$ clay & 0.24 & 0.17 \\
20/80/7 + 3\% clay & 0.40 & 0.39 \\
$0 / 100 / 7+3 \%$ clay & 0.43 & 0.43 \\
$80 / 20 / 10+3 \%$ clay & 0.08 & 0.04 \\
$50 / 50 / 10+3 \%$ clay & 0.23 & $0.25^{\mathrm{a}}$ \\
$20 / 80 / 10+3 \%$ clay & 0.36 & $0.38^{\mathrm{a}}$ \\
$80 / 20 / 15+3 \%$ clay & 0.08 & 0.04 \\
$50 / 50 / 15+3 \%$ clay & 0.24 & $0.26^{\mathrm{a}}$ \\
20/80/15 + 3\% clay & 0.35 & $0.39^{\mathrm{a}}$ \\
$80 / 20 / 7+5 \%$ clay & 0.21 & 0.03 \\
$50 / 50 / 7+5 \%$ clay & 0.24 & $0.17^{\mathrm{a}}$ \\
20/80/7 + 5\% clay & 0.36 & $0.39^{\mathrm{a}}$ \\
$80 / 20 / 10+5 \%$ clay & 0.07 & 0.04 \\
$50 / 50 / 10+5 \%$ clay & 0.18 & $0.25^{\mathrm{a}}$ \\
$20 / 80 / 10+5 \%$ clay & 0.39 & $0.38^{\mathrm{a}}$ \\
$80 / 20 / 15+5 \%$ clay & 0.10 & 0.04 \\
$50 / 50 / 15+5 \%$ clay & 0.17 & $0.26^{\mathrm{a}}$ \\
$20 / 80 / 15+5 \%$ clay & 0.35 & $0.39^{\mathrm{a}}$ \\
\hline
\end{tabular}

a Appearance of the polyethylene and PET melting peaks but not of the PET crystallization peak.

compatibilizer and those with $15 \%$ compatibilizer plus 3 or $5 \%$ clay showed $H$ values not far from the ones derived by means of eq. (5).

With regard to the hardness variation as a function of both the composition and the compatibilizer content, as in the previously studied blends, this was due to the decrease in the crystalline hardness, which, in turn, was caused by the higher $\sigma_{e}$ of the crystals due to the disorder introduced by the blending process and by the compatibilizer. However, this effect was smaller in the presence of clay.

\section{CONCLUSIONS}

1. From the preceding results, it was clear that PET was incompatible with both iPP and HDPE. However, the presence of SEBS-MAH allowed us to compatibilize these polymers.

2. Whereas the initially amorphous PET was capable of crystallizing to a certain extent in the presence of iPP, probably as a consequence of the blending process (the PET enthalpic balance was always positive), the crystallizability of iPP was strongly reduced by the PET component. Nevertheless, in the presence of the compatibilizer SEBS-MAH, the iPP chains became more flexible so that they could crystallize much more easily. However, the hardness of the blends strongly decreased as the compatibilizer content increased.
3. In the pure PET/iPP blends, the increase in $H$ as a function of PET content was simply due to the composition. In case of compatibilized blends, the hardness behavior was explained by the assumption that $\sigma_{e}$ of the iPP crystals notably increased with the addition of SEBS$\mathrm{MAH}$, which was an amorphous material constituted by a short chain of elastomeric character. In addition, the clay seemed to have a nucleating effect on the iPP and also induced a
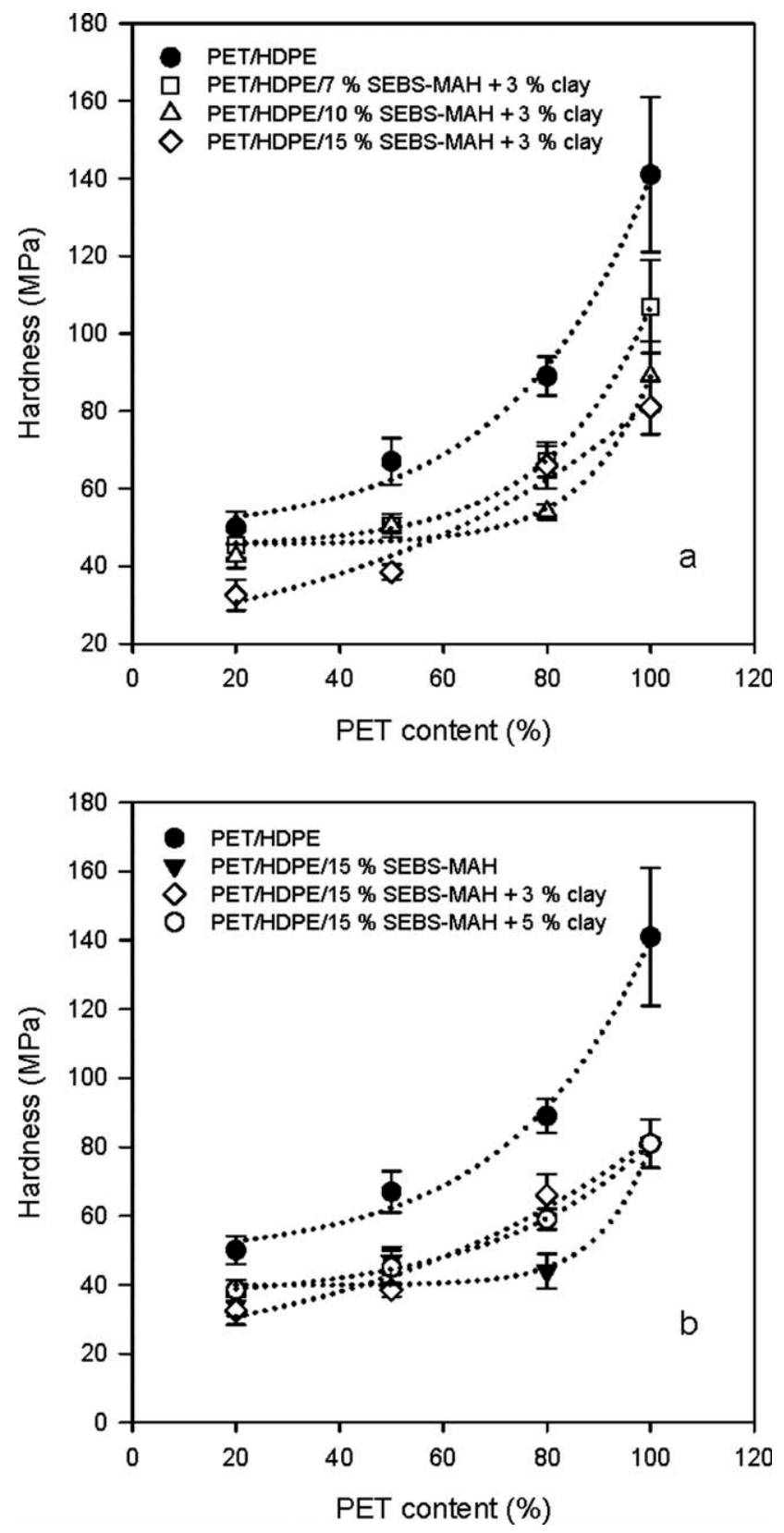

Figure 8 Dependence of the hardness on the PET content: (a) PET/HDPE blends (pure and with different proportions of the compatibilizer plus 3\% clay) and (b) PET/ HDPE blends (pure, with $15 \%$ compatibilizer, and with $15 \%$ compatibilizer and 3 or $5 \%$ clay). 
slight hardness increase in the compatibilized blends.

4. The crystallinity of the PET/HDPE blends (pure blends, blends with compatibilizer, and blends with compatibilizer plus clay) depended only on their composition. In this case, we did not find any nucleating effect of the clay upon the HDPE.

5. Whereas the initially amorphous PET was capable of crystallizing in the presence of HDPE, with the enthalpic balance of PET being always positive, the PET did not affect the crystallizability of the HDPE component. Moreover, as happened with the PET/iPP blends, the presence of the SEBS-MAH strongly induced a hardness decrease in the blends, probably through an increase in $\sigma_{e}$ of the HDPE crystals.

6. Finally, similarly to the PET/iPP blends, the addition of $3-5 \%$ clay induced an increase in the hardness of the compatibilized blends.

\section{References}

1. Polymer Recycling: Science, Technology and Applications; Scheirs, J., Ed.; Wiley: Chichester, England, 1998.

2. Plastics Recycling: Products and Processes; Erigh, R. J., Ed.; Hanser: New York, 1992.

3. Polymer Blends: A Comprehensive Review; Robeson, L. M., Ed.; Hanser: Munich, 2007.

4. Polymer Blends; Paul, D. R.; Bucknall, C. B., Eds.; Wiley: New York, 2000; Vols. 1 and 2.

5. Polymer Blends and Alloys; Shonaike, G. O.; Simon, G. P., Eds.; Marcel Dekker: New York, 1999.

6. Utracki, L. A. Can J Chem Eng 2002, 80, 1008.

7. Sinha Rao, S.; Okamoto, M. Prog Polym Sci 2003, 28, 1539

8. Rohlmann, C. O.; Failla, M. D.; Quinzani, L. M. Polymer 2006, 47,7795 .
9. Palza, H.; Vergara, R.; Yazdani-Pedram, M.; Quijada, R. J Appl Polym Sci 2009, 112, 1278.

10. Giannelis, E. P. Adv Mater 1996, 8, 29.

11. Hull, D. An Introduction to Composite Materials; Cambridge University Press: Cambridge, England, 1981; Chapter $5, \mathrm{p} 81$.

12. Baltá Calleja, F. J.; Fakirov, S. Microhardness of Polymers; Solid State Science Series; Cambridge University Press: Cambridge, England, 2000; Chapter 1, p 3.

13. Berdjane, K.; Berdjane, Z.; Rueda, D. R.; Benachour, D.; BaltáCalleja, F. J. J Appl Polym Sci 2003, 89, 2046.

14. Krache, R.; Benachour, D.; Cagiao, M. E.; Baltá Calleja, F. J.; Bayer, R. K.; Tschöpe, F. Int J Polym Mater 2003, 52, 939.

15. Fakirov, S.; Baltá Calleja, F. J.; Boyanova, M. J Mater Sci Lett 2003, 22, 1011.

16. Adhikari, R.; Michler, G. H.; Cagiao, M. E.; Baltá Calleja, F. J. J Polym Eng 2003, 23, 177

17. Baltá Calleja, F. J.; Cagiao, M. E.; Adhikari, R.; Michler, G. H. Polymer 2004, 45, 247.

18. Mina, M. F.; Ania, F.; Baltá Calleja, F. J.; Asano, T. J Appl Polym Sci 2004, 91, 205.

19. Mina, M. F.; Ania, F.; Huy, T. A.; Michler, G. H.; Baltá Calleja, F. J. J Macromol Sci Phys 2004, 43, 947.

20. Boyanova, M.; Mina, M. F.; Baltá Calleja, F. J.; Fakirov, S. e-Polymers 2003, 47, 1.

21. Mina, M. F.; Haque, M. E.; Baltá Calleja, F. J.; Asano, T.; Alam, M. M. J Macromol Sci Phys 2004, 43, 1005.

22. Adhikari, R.; Godehardt, R.; Lebek, W.; Frangov, S.; Michler, G. H.; Radusch, H.-J.; Baltá Calleja, F. J. Polym Adv Technol 2005, 16, 156.

23. Bouhelal, S.; Cagiao, M. E.; Khellaf, S.; Benachour, D.; Baltá Calleja, F. J. J Appl Polym Sci 2008, 109, 795.

24. ATHAS Databank. http://athas.prz.rzeszow.pl (accessed Sept 2009).

25. Flores, A.; Aurrekoechea, J.; Gensler, R.; Kausch, H. H.; Baltá Calleja, F. J. Colloid Polym Sci 1998, 276, 786.

26. Celli, A.; Zanotto, E. D. Thermochim Acta 1995, 269, 191.

27. Baltá Calleja, F. J.; Fakirov, S. Microhardness of Polymers; Solid State Science Series; Cambridge University Press: Cambridge, England, 2000; Chapters 4 and 5.

28. Baltá Calleja, F. J.; Santa Cruz, C.; Bayer, R. K.; Kilian, H. G. Colloid Polym Sci 1990, 268, 440. 